\title{
Contributors to Systematic Microbiology
}

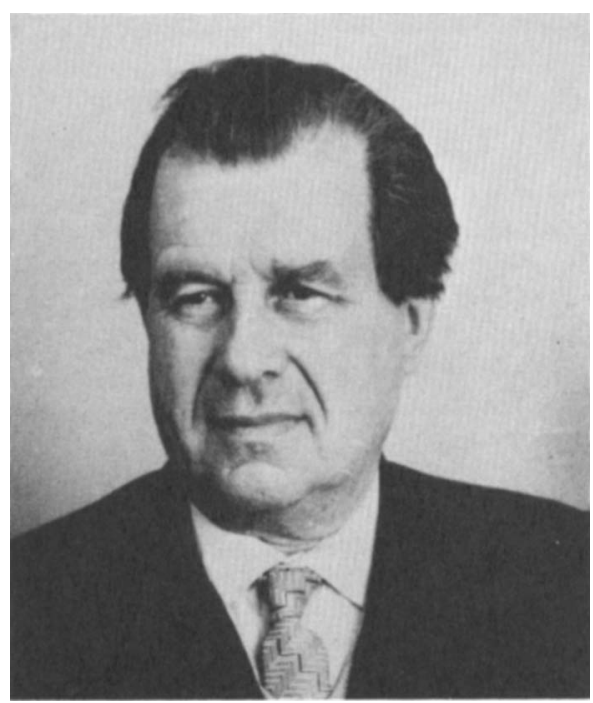

\section{Nikolai Alexandrovitch Krasil'nikov}

\section{6-1973}

N. A. Krasil'nikov was born on December 19, 1896, in the village of Podveski, Kaluga region, USSR, to the family of a peasant. After service in the Red Army he received his higher education and graduated from the Medical Institute in Leningrad in 1923. As a graduate student, Krasil'nikov started his studies in microbiology under the supervision of the late Academician G. A. Nadson in the Microbiological Laboratory of the USSR Academy of Science, then located in Leningrad.

In the mid-1920s a group of young, able, and enthusiastic researchers surrounded Dr. Nadson, then head of the Laboratory. Some of these people (including Krasil'nikov) later formed the nucleus of the Institute of Microbiology of the USSR Academy of Science when the Laboratory was transferred to Moscow and reorganized in 1933. A rather wide spectrum of research topics was assembled in Nadson's laboratory, and almost each research project was represented by an actively working young microbiologist of a quite definite personality. Common to all members of the group for a number of years was the interest in microbial variability, both spontaneous and induced. This was probably rooted in the impact which the pioneering studies of Nadson and Filippov in Xray-induced mutation in yeast had made on the
Russian microbiological community of the time.

Dr. Krasil'nikov started his research career as a "hunter for microbes." He studied numerous aspects of a variety of microorganisms: yeasts, sporeforming bacteria, free-living and symbiotic nitrogen-fixing bacteria, etc. During his formative period he enriched the scientific literature with many interesting publications containing descriptions of new microorganisms, their ecology, variability, etc. He gained very wide experience in work with diverse microorganisms, and he developed a liking for novel facts and explanations.

As a mature researcher, Krasil'nikov entered the field of actinomycetes in the early 1930 s. It is difficult to say at the moment which reasons motivated his choice-whether it was the abundance of actinomycetes in arid soils of the Saratov region, which he studied at that time, or whether the beautifully colored colonies of actinomycetes caught the eye of this microbiologist, for whom an interest in painting always ranked next to his interest in microbes. One is inclined to think that both these motives were dominated by the image of actinomycetes being really "little-known" microorganisms at that time, attracting the attention of just four or five devoted pioneers throughout 
the world. Whatever the reasons for his choice, it was the work with actinomycetes and antibiotics that brought the most fame to the name of N. A. Krasil'nikov.

The creative individuality of Krasil'nikov was, in my opinion, most fully expressed in his studies with actinomycetes, systematically pursued for more than two decades. Some characteristic aspects of his approach might be mentioned. First of all, there was a clear tendency to study a "natural group of organisms," each taken in the whole complexity of a biological individuality. Some modern microbiologists would probably not approve of such a formulation of ultimate research goals, their unprecise character being rather apparent. It is true that "organism-oriented" research, especially during its early stages, sometimes lags behind in terms of standard "countable" achievements of a "problem-oriented" research with clearly formulated goals. It seems, however, that it is in later stages that the former begins to bear its fruits, sometimes quite novel and unexpected, and convinces most of the skeptics that the two approaches are in fact of obligatory complementary nature. The naturalistic way of thinking implied full attention to the whole organism without putting special emphasis on a particular technique for studying it. The reader of Krasil'nikov's papers published between 1930 and 1940 will find numerous examples of this attitude. One is a strict preference for studying growth cycles of microorganisms by using the "hanging drop" technique and the apparent dislike for the "fixed and stained smears"-the technique which was at the peak of its popularity at that time.

On the other hand, starting with actinomycetes, N. A. Krasil'nikov made an outstanding effort to put together an enormous body of information on microorganisms, to bring it into perspective and develop a system of classification that would be as close to a natural one as possible.

In developing his system of microorganisms, Krasil'nikov placed heavy emphasis on comparison of their developmental patterns as well as on characteristics of spontaneous and induced variants. Production of similar forms in the course of variability was taken as an indication of relatedness. An effort was thus made to rationalize the system by introducing empirical elements in probing the supposed "horizontal" and "vertical" relationships among microorganisms.

In the mid 1930 s some outstanding microbiologists apparently thought that a "natural" system of classification of microorganisms was likely to emerge rather soon. The eighth edition (1974) of Bergey's Manual of Determinative Bacteriology clearly demonstrates how far we are even now from such a system and how difficult it would be to reach any system by compromising strongly individual attitudes. Besides other obvious things, the reasons for these difficulties may well lie within the psychological roots of scientific creativity. As Albert Einstein wrote in his outstanding Motiv des Forschens, the image of the world ("Bild der Welt") at which the true scientist might even involuntarily aim would most often be characterized by ". . .supreme purity, clarity, and certainty, at the cost of completeness." One is led to wonder, indeed, whether the naturalistic approach in studying living organisms and the efforts to develop a system of their classification are quite complementary psychologically and whether their possible conflict might in fact constitute something of an inner driving force for developments in the whole field of systematic bacteriology. The work with actinomycetes and related organisms, as well as the efforts to develop a general system of classification of microorganisms, was probably among those activities of Dr. Krasil'nikov that aroused the most interest outside the USSR. The late R. E. Buchanan probably alluded to them while presenting Krasil' nikov with a copy of the Index Bergeyana bearing the inscription: "To the dean of Soviet microbiologists."

No less an impact inside the country was made by studies of Krasil'nikov and his associates which lead to the discovery, in 19361939 , of the production by actinomycetes of antibiotic substances. Results of experiments called for prompt trials to use the substances in medicine and agriculture. However, World War II drastically interfered with continuation of the experiments and blocked the very important efforts to purify and characterize the substances chemically. Furthermore, Krasil'nikov's large collection of actinomycetes was lost.

After the war the studies of Dr. Krasil'nikov and his co-workers provided a very substantial portion of the necessary background for the development of the antibiotics industry in the USSR. Krasil'nikov was one of the first to call for application of antibiotics in plant protection and animal breeding; the same time, he strongly opposed the use in agriculture of preparations that could be used in medicine.

He was always deeply involved in the problems of soil microbiology. The subject matter of his publications in the area ranged from weathering of rocks to use of microbial fertilizers. These interests were furthered with the es- 
tablishment, in 1953, of the Chair for Soil Biology, at the faculty of Soil Science, Moscow State University. Krasil'nikov headed the chair from 1953 until 1973. Research work was done here on the interaction of microorganisms with higher plants and on several other topics. Pioneering studies on adsorption of soil microorganisms, soil fungi and yeasts, and anaerobic sporeforming bacteria (to name only a few) are still continued by former students and associates of Krasil'nikov. Dozens of microbiologists graduated from the University under the supervision of N. A. Krasil'nikov. Several others became associated with him during long periods of their careers. Krasil'nikov realized the growing potential of applied microbiology and encouraged his associates and students to enter such important fields as transformation of organic molecules by microorganisms, production of plant growth-promoting substances, amino acids, insecticides, etc. As a research leader, Krasil'nikov possessed the necessary degree of tolerance toward the individualities of the people immediately around him, and this capacity served to broaden the impact of his activities.

Together with his associates, Krasil'nikov wrote more than 300 papers. The list of his most important books includes: Actinomycetes and Related Organisms, Actinomycetales (1938); Determinative Manual for Actinomycetes (1941); Manual for Determination of Bacteria and Actinomycetes (1949; translated into German and partially translated into English); Actinomycetes-Antagonists and Antibiotic Substances (1950); Soil Microorganisms and Higher Plants (1958; translated into Chinese and English); and Ray Fungi/Higher Forms (1970). Krasil' nikov initiated the publication of two collected volumes (1960; 1965): "Biology of Individual Groups of Actinomycetes" (both translated into English). Some important books by non-Russian authors (including R. Dubos" "The Microbial Cell") appeared in a Russian translation which was edited by N. A. Krasil'nikov.

The activities of N. A. Krasil'nikov were highly valued in the USSR. He was elected Corresponding Member of the USSR Academy of Science, was decorated by Lenin, and was the recipient of other orders and medals. He was awarded the State (1950), Metchnikoff (1952), and Lenin (1971) prizes and served on several scientific and advisory councils and boards.

L. V. Kalakoutskii Moscow 